Research, Society and Development, v. 9, n.1, e21911551, 2020

(CC BY 4.0) | ISSN 2525-3409 | DOI: http://dx.doi.org/10.33448/rsd-v9i1.1551

\title{
O ensino a distância no Brasil: alguns apontamentos
}

Distance learning in Brazil: some notes

Aprendizaje a distancia en Brasil: algunas notas

Recebido: 24/08/2019 | Revisado: 26/08/2019 | Aceito: 05/09/2019 | Publicado: 04/10/2019

\section{Stéfani Martins Fernandes}

ORCID: https://orcid.org/0000-0001-6362-4273

Universidade Franciscana, Brasil

E-mail: stefanimartinsfernandes@gmail.com

Leonardo Guedes Henn

ORCID: https://orcid.org/0000-0002-0840-1189

Universidade Franciscana, Brasil

E-mail: lghenn@gmail.com

Liane Batistela Kist

ORCID: https://orcid.org/0000-0003-2317-2545

Universidade Franciscana, Brasil

E-mail: lianebatistela@gmail.com

\section{Resumo}

O presente trabalho faz parte da dissertação, já defendida, do Mestrado em Ensino de Humanidades e Linguagens (MEHL), da Universidade Franciscana (UFN). Ele é uma pesquisa qualitativa, do tipo revisão bibliográfica, com o objetivo de traçar um panorama histórico geral das diferentes formas de desenvolvimento do ensino a distância no Brasil. Para tanto, foram usadas obras de autores que versam sobre a temática, tais como J. R. M. Alves (1994), Maia e Mattar (2007), B. Carvalho (2014), Batista e Souza (2015) e Amarilla (2011). Metodologicamente, este estudo foi dividido em três partes. A primeira envolve questões relativas ao conceito de EAD, visando os termos que mais se destacam na maior parte dos conceitos sobre EAD. A segunda parte versa sobre a trajetória histórica desta modalidade, com foco na sua atuação no Brasil. Por fim, a terceira parte apresenta os recursos que os ambientes de interação e formação informal, por meio virtual, oferecem. Além disso, foram consultadas as leis referentes a temática da pesquisa. Observa-se que os potenciais destes ambientes virtuais de formação ainda estão em processo de construção e reflexão, tanto em 
relação as suas contribuições com os cursos a distância, quanto nas pesquisas acadêmicas que envolvem a temática.

Palavras-chave: Ensino a distância; Ambientes virtuais; Histórico.

\begin{abstract}
The present work is part of the dissertation, already defended, of the master in teaching of humanities and languages (MEHL), of the Franciscan University (UFN). It is a qualitative research, of the bibliographic revision type, with the objective of drawing a general historical panorama of the different forms of development of distance learning in Brazil. For this purpose, we used works by authors who deal with the theme, such as J. R. M. Alves (1994), Maia and Mattar (2007), B. Carvalho (2014), Batista and Souza (2015) and Amarilla (2011). Methodologically, this study was divided into three parts. The first involves questions related to the concept of EAD, aiming the terms that most stand out in most of the concepts about EAD. The second part deals with the historical trajectory of this modality, focusing on its performance in Brazil. Finally, the third part presents the resources that interactive environments and informal training, through virtual means, offer. In addition, the laws referring to the research theme were consulted. It is observed that the potentials of these virtual training environments are still in the process of construction and reflection, both in relation to their contributions with the distance courses, as in the academic researches that involve the theme.
\end{abstract}

Keywords: Distance learning; Virtual environments; Historic.

\title{
Resumen
}

La obra actual forma parte de la disertación, ya defendida, del Máster en Enseñanza de Humanidades y Lenguas (MEHL), de la Universidad Franciscana (UFN). Es una investigación cualitativa, del tipo de revisión bibliográfica, con el objetivo de dibujar un panorama histórico general de las diferentes formas de desarrollo del aprendizaje a distancia en Brasil.. Para ello, utilizamos obras de autores que tratan el tema, como J. R. M. Alves (1994), Maia y Mattar (2007), B. Carvalho (2014), Batista y Souza (2015) y Amarilla (2011). Metodológicamente, este estudio se dividió en tres partes. La primera se refiere a cuestiones relacionadas con el concepto de EAD, apuntando a los términos que más destacan en la mayoría de los conceptos sobre EAD. La segunda parte trata de la trayectoria histórica de esta modalidad, centrándose en su desempeño en Brasil. Por último, la tercera parte presenta los recursos que ofrecen los entornos interactivos y la formación informal, a través de medios virtuales. Además, se consultaron las leyes que se refieren al tema de la investigación. Se observa que las potencialidades de estos entornos de formación virtual aún están en proceso de construcción y reflexión, tanto en relación con sus aportaciones con los cursos a distancia, como en las investigaciones académicas que involucran el tema.

Palabras clave: Aprendizaje a distancia; Entornos virtuales; Histórico. 


\section{Introdução}

O Ensino a Distância - EAD - está em uma trajetória ascendente em relação à oferta, especialmente nas Instituições de Ensino Superior (IES). Em termos gerais, o EAD tem como objetivo facilitar o inscrito em algum curso desta modalidade. Com isso, levar a mesma qualidade do ensino presencial, mas com a diferença de se ajustar aos dias e horários do estudante.

Porém, essa não é uma modalidade de ensino nova. Há registros de cursos à distância feitos a partir de cartas, chegando aos dias de hoje, com o uso da internet. A cada período histórico, pode-se perceber que o EAD se ampliava, em relação aos recursos de uso, às evoluções das tecnologias, desde correspondências, passando ao uso de rádio, televisão, internet. Nos últimos anos, essa modalidade ganha destaque com o uso de outros meios digitais.

Em relação aos últimos anos, percebe-se que os estudos sobre a educação virtual e espaços não formais de ensino cresceram significativamente, apesar de ambos possuírem práticas mais antigas, como o ensino por correspondência. Há vários autores e trabalhos entre livros e artigos - que abordam essas temáticas. Porém, essas pesquisas limitam-se aos conteúdos ensinados no ensino regular.

A partir destas reflexões, se construiu uma revisão bibliográfica, com o objetivo de traçar um panorama histórico geral das diferentes formas de desenvolvimento do ensino a distância no Brasil. Para tanto, foram usadas obras de autores que versam sobre a temática, tais como J. R. M. Alves (1994), Maia e Mattar (2007), B. Carvalho (2014), Batista e Souza (2015) e Amarilla (2011).

Este estudo foi dividido em três partes. A primeira envolve questões relativas ao conceito de EAD, visando os termos que mais se destacam na maior parte dos conceitos sobre EAD. A segunda parte versa sobre a trajetória histórica desta modalidade, com foco na sua atuação no Brasil. Por fim, a terceira parte apresenta os recursos que os ambientes de interação e formação informal, por meio virtual, oferecem. Além disso, foram consultadas as leis referentes a temática da pesquisa. Observa-se que os potenciais destes ambientes virtuais de formação ainda estão em processo de construção e reflexão, tanto em relação as suas contribuições com os cursos a distância, quanto nas pesquisas acadêmicas que envolvem a temática. 


\section{Metodologia}

Esta pesquisa é de cunho qualitativo, utilizando a pesquisa bibliográfica, a partir dos referenciais de Michel (2015) e Parreira e Shitsuka (2018). Para a coleta das fontes, utilizouse como critério livros, artigos, teses e dissertações que versassem sobre a temática desta pesquisa, utilizando as seguintes palavras-chave: ensino a distância, educação a distância, EAD, ambientes virtuais, histórico EAD. Além disso, as datas de publicação das fontes foram limitadas a um período de quinze anos. Porém, pelo fato da maioria dos trabalhos encontrados citarem autores clássicos sobre a temática, de período anterior ao já determinado, os mesmos foram incorporados ao trabalho.

\section{Questões relativas ao conceito sobre EAD}

São necessárias apenas três letras - EAD - para abarcar vários significados. Educação a distância, ensino a distância, educação aberta a distância, entre outros. Mesmo se diferenciando em alguns aspectos, todas essas nomenclaturas abarcam conceitos semelhantes. Há vários autores que pesquisam a EAD tendo como enfoque o estudo do conceito sobre a mesma (Luzzi, 2007; Behar, 2009; Vilaça, 2010; L. Alves, 2011; B. Carvalho, 2014).

Para Behar (2009), a EAD, assim como outras modalidades de ensino, é uma forma de promover a "aprendizagem organizada, que se caracteriza, basicamente, pela separação física entre professor e alunos e a existência de algum tipo de tecnologia de mediação para estabelecer a interação entre eles" (Behar, 2009, p. 16). Ou seja, para a autora, em um ensino à distância, é imprescindível o uso de uma tecnologia para a comunicação. Luzzi (2007), em uma pesquisa que analisou mais de quarenta definições sobre $\mathrm{EAD}$, aponta que a maioria dos autores analisados tem uma espécie de definição geral sobre EAD. Nisso há duas características em comum, sendo a primeira delas a separação - de forma física - e o uso dos meios de comunicação. Além disso, metade das definições apresentam uma preocupação didática e/ou pedagógica sem a EAD. Assim,

A segunda constatação resulta em observar que as principais categorias que expressam a dimensão didático-pedagógica do processo educativo encontram-se abaixo dos $40 \%$ de frequência, ou seja, tutoria, comunicação bidirecional, planejamento e organização, métodos didáticos e reuniões presenciais são aspectos relegados a um segundo plano, que sequer chegam à metade da amostra (Luzzi, 2007, p. 2014). 
A questão metodológica fica em segundo plano quando se constrói uma definição para ensino a distância. A preocupação está centrada em usar um dispositivo tecnológico - móvel ou não - para o acesso aos cursos ofertados. Isso gera uma lacuna sobre esta modalidade, pois a partir do momento em que não há em planejamento metodológico, a estrutura de um curso nesta modalidade perde parte de seu valor em relação ao ensino que ela propõe. Atualmente há cursos preocupados com a metodologia utilizada em seus cursos. Isso influencia na forma como a EAD é entendida, apesar de não haver um conceito padrão.

Luzzi (2007) ainda aponta a dificuldade de a EAD apresentar uma definição fixa de conceituação. Nisso,

O conceito de educação a distância apresenta dificuldades particulares para sua definição em razão da diversidade de características que os sistemas possuem denominações, estruturas, metodologias, organização -, que acabam por configurar não só diferentes definições, mas também realidades educativas que correspondem às visões de mundo que elas adotam (Luzzi, 2007, p. 96).

Há várias particularidades que influenciam em várias definições. Essas têm relação contexto em que está inserida. Isso vai definir o seu conceito. Cada instituição que oferta cursos, além dos autores que pesquisam sobre este tema, apresentam formas diferentes de conceituar o ensino/educação a distância. É importante que se tenha uma definição sobre a modalidade, pois ela irá nortear a forma como os cursos irão se desenvolver.

Para Mill e Oliveira (2014) a definição e conceituação sobre EAD caminham juntamente com as pesquisas sobre a mesma. Nesse contexto, o fato de a EAD "ser um campo demasiado complexo e ainda em definição, o desafio para a realização de pesquisas sobre EAD começa a ser mesmo na definição do foco do estudo" (Mill \& Oliveira, 2014, p. 19).

Segundo os autores, a limitação da conceituação ainda não madura sobre EAD, bem como a forma e, que a mesma se implementa, afeta diretamente as temáticas pesquisadas na área. Os mesmos observaram que a maioria das pesquisas não trabalham a EAD, enquanto área de conhecimento. Uma das causas apontadas pelos autores pode decorrer do fato de a mesma ainda estar em formação quanto a sua definição e conceito.

Batista e Souza (2015) salientam que as terminologias para EAD são utilizadas de forma indiscriminada, sem estudos sobre o que elas significam. Para os autores, a EAD gera, de certa forma, mais flexibilidade em seu acesso e uso. Com isso a "grande vantagem dessa ferramenta é o acesso remoto, o usuário pode aprender a desenvolver atividades a qualquer hora e em qualquer lugar pelo usufruto de dispositivos próprios" (Batista \& Souza, 2015, p. 13). 
Research, Society and Development, v. 9, n.1, e21911551, 2020

(CC BY 4.0) | ISSN 2525-3409 | DOI: http://dx.doi.org/10.33448/rsd-v9i1.1551

Algumas das definições e conceitos sobre EAD apresentam, em sua interpretação, uma espécie entre de divergência entre EAD e o ensino regular presencial. Vilaça (2010) adverte sobre essa oposição popularmente difundida entre EAD e o chamado ensino formal presencial.

Para uma melhor contribuição para o conceito de EAD, o planejamento desta modalidade é de suma importância. A EAD não deve ser vista e planejada de forma "solta". Assim, Vilaça (2010) aponta que, quando devidamente planejada e estudada, as possibilidades de equívoco e confusão são mínimas. Por isso,

É necessário que professores e estudantes estejam devidamente informados sobre as características e potencialidades desta modalidade de ensino, de forma a evitar conceitos equivocados e, até mesmo, crenças e preconceitos (Vilaça, 2010, p. 100).

Com relação ao uso do termo distância, Vilaça (2010) destaca que não existe apenas uma compreensão de distância na EAD, apesar de a mesma ser um conceito-chave. Segundo o autor,

A distância deve ser compreendida basicamente como separação espacial (geográfica/local) entre participantes do processo educacional, sejam estes alunos ou professores. Em aulas por videoconferência, é comum que os alunos estejam juntos, mas em lugar diferente do professor. Por outro lado, quando o estudo ocorre pela internet, é comum alunos e professores estejam em locais diferentes e acessem o curso e os materiais e recursos didáticos em momentos diferentes. Estes dois exemplos ilustram que há diferentes possibilidades de distanciamento entre alunos e professores (Vilaça, 2010, p. 91).

A distância se apresenta de várias formas. O ensino a distância não deve ser compreendido somente a partir do ponto de vista geográfico, quando o professor está em um lugar e os alunos em outro, o que é comum em cursos dessa modalidade. Há de se considerar a distância em relação ao tempo. Tanto alunos quanto professores acessam os cursos em períodos diferentes, onde o professor insere os conteúdos e materiais correspondentes em um momento e os alunos podem acessar na mesma hora, ou em período adequando à sua rotina. Isso significa que cada um destes participantes compreendem o tempo de acesso de formas diferentes.

B. Carvalho (2014, p. 124), por sua vez, destaca a "separação entre professores e alunos pela distância e pelo tempo com mediação dos processos de ensino e aprendizagem por recursos tecnológicos". Amarilla (2011) compreende o termo distância envolvendo a relação entre professor e aluno - algo mencionado na maioria das pesquisas envolvendo EAD - entre aluno e aluno e, por último, aluno e material. Com isso, 
o sentido de "distância", dentro de um processo de ensino-aprendizagem, pode ser entendido a partir de três relações: a distância entre professor-aluno, aluno-aluno, aluno-material (embora, cabe ressaltar, o termo distância tenha, dentro desse processo, uma definição relativa, pois a sensação de distância tem a mesma métrica que a distância espacial, isto é, um aluno, um professor, embora presente, pode estar mais distante dos seus pares do que aqueles ausentes) (Amarilla, 2011, p. 48).

Nesse sentido, a palavra distância assume um significado maior, tornando-se necessário que suas interpretações nas definições sobre EAD passem por um processo de reflexão. A partir disso, deve-se atentar para um dos significados da $\mathrm{EAD}$, em quaisquer de suas nomenclaturas. Para Amarilla (2011),

A Educação a Distância requer a compreensão de que é um processo de ensinoaprendizagem apontado para uma só dimensão: a proximidade do aluno, não no sentido espaço-temporal, mas no sentido do exercício da autonomia, da participação e da colaboração no processo de ensino-aprendizagem. É o aluno motivado e "próximo" o foco principal de tal processo, a partir do conhecimento de suas características socioculturais, das suas experiências e demandas (Amarilla, 2011, p. 48).

Para tanto, é necessário que a comunicação - e seu modo de mediação - seja levado em conta. Amarilla (2011) propõe que os novos meios de desenvolver a comunicação devem objetivar uma maior autonomia, levando aos processos de colaboração entre os participantes. Atualmente, as tecnologias digitais está sendo o recurso mediador mais utilizado.

L. Alves (2011) aponta que as tecnologias digitais estão irremediavelmente atreladas ao ensino a distância. Com isso, a EAD fica inviável, atualmente, sem as mesmas. Santos (1999), ao enfatizar a internet, ressalta que a mesma permite um acesso a trocas de conhecimento mais longas e em pouco tempo. Assim,

De forma diferente das inovações tecnológicas surgidas nos últimos anos, a Internet rompe as barreiras geográficas de espaço e tempo, permite o compartilhamento de informações em tempo real e apoia a cooperação e a comunicação, também em tempo real (Santos, 1999, p. 75).

Por acompanhar, na maioria das vezes, as novas tecnologias, a EAD é vista como "avançada" em relação ao "atraso" do ensino tradicional, que para o autor é entendido como o ensino formal. Contudo, não há garantias de que, com um aparato tecnológico moderno, haverá um ensino inovador e vice-versa, pois "a tecnologia por si só não pode garantir qualidade ao ensino. A qualidade da educação depende de uma ampla variedade de fatores. Em outras palavras, é possível ser "inovador" no ensino dito "tradicional"” (Vilaça, 2010, p. 96). Os aparatos tecnológicos, mais especificamente os digitais, não garantem um ensino inovador, pois podem ser usados nos mesmos moldes do ensino tradicional, perdendo suas características de originalidade. 
Research, Society and Development, v. 9, n.1, e21911551, 2020

(CC BY 4.0) | ISSN 2525-3409 | DOI: http://dx.doi.org/10.33448/rsd-v9i1.1551

Mesmo não havendo uma dicotomia entre essas duas modalidades de ensino, ainda há aspectos que as tornam diferenciadas. Silva, Melo e Muylder (2015) apontam que, pelas próprias conceituações que a EAD possui, a mesma já se difere muito em relação ao ensino, chamado pelas autoras de tradicional - ou formal presencial.

Além da distância, as várias definições de EAD enfatizam dois elementos importantes, o professor(a) e aluno(a). Corroborando com Vilaça (2010), Garcia e P. M. Carvalho (2015) tratam da questão da separação não só física, mas geográfica e temporal, entre professor(a) e aluno(a).

Para Silva et al. (2015), essa modalidade de ensino tem como principal norteador o aluno. Nisso ele "é o responsável pelo seu ritmo de estudo e pela carga horária destinada ao curso. Para tanto, o perfil do aluno será um grande influenciador de disciplina e do comprometimento empregado no curso" (Silva, Melo, \& Muylder, 2015, p. 221). O aluno se mostra como norteador da estrutura dos cursos a distância, pois é em torno dele que eles se desenvolvem. As instituições que ofertam cursos a distância devem moldá-los e acordo com o perfil majoritário de seus alunos. Isso torna natural a familiaridade deles com estes cursos.

Segundo Garcia e P. M. Carvalho (2015), a EAD tem certa valorização por parte dos alunos. Dentre esses motivos estão a flexibilidade de tempo e lugar. Porém, os autores alertam que as mesmas exigem, de cada aluno, "disciplina e boas estratégias de estudo" (Garcia \& P. M. Carvalho, 2015, p. 210).

Em relação ao professor, Garcia e P. M. Carvalho (2015) apontam que o mesmo teve um papel de transmissão. Para os autores,

\begin{abstract}
A educação a distância foi conhecida por muito tempo como o processo educacional que ocorria sem a presença do professor, na qual todo o material instrucional era enviado por correio e que o aluno deveria realizar seus estudos de forma individual e autônoma, a partir do material recebido, geralmente impresso, que havia sido preparado especialmente para aquele curso, com o envio posterior, pelo aluno, de lições ou trabalhos por correspondência (Garcia \& P. M. Carvalho, 2015, p. 210).
\end{abstract}

Não havia uma relação direta entre professor e alunos. O que ocorria era apenas o envio de conteúdo/atividade e respostas. O ensino, neste sentido, ocorria de forma mecanizada. Não havia momentos em que dúvidas em relação aos conteúdos eram resolvidas. A avaliação, enviada pelos alunos, eram suficientes para traçar uma resposta positiva aos cursos. Nisso, o professor da EAD se assemelhava, de certa forma, ao professor tradicional do ensino presencial.

Porém os autores apontam para uma ampliação das funções do professor que trabalha com EAD na atualidade. Segundo Garcia e P. M. Carvalho (2015) este professor "tem seu 
papel ampliado de simples transmissor de informações para outros como: gestor do processo, criador de material instrucional, facilitador do processo, conselheiro, guia, etc." (Garcia \& P. M. Carvalho, 2015, p. 212). As demandas que acompanham o contexto atual exigem que professor de cursos a distância se aproprie e se familiarize com todo o processo que envolve planejamento, organização, acesso e relação dos cursos com aos alunos. Com isso, essas funções podem ser compartilhadas com outros professores, que podem assumir funções diferentes, como criação de conteúdo, avaliador, gestor, tutor para dúvidas dos alunos, entre outros. Essa divisão deve ser ocorrer de forma que todos tenham a mesma perspectiva em relação aos cursos.

Vale ressaltar que o papel do professor em EAD caminha, juntamente, com os avanços em relação ao papel do professor(a) na modalidade presencial.

Durante várias décadas - e mesmo na atualidade - ainda ocorrem dificuldades em apresentar um conceito fixo sobre EAD. Isso ocorre devido a própria ideia dos autores sobre esta modalidade, bem como o papel de cada ator deste processo, como o professor e os alunos. Outro aspecto importante são as nomenclaturas já mencionadas, sendo que cada uma também vai apresentar uma definição que, mesmo tendo similaridades, possuem características singulares a cada nomenclatura. Dentro das conceituações apresentadas por cada autor estudado, nota-se que o papel da EAD, juntamente com os participantes desta modalidade, ganha novas atribuições e funções.

A EAD se torna uma modalidade de ampla expansão pelo uso da internet, começando pelos anos 1990. A partir dos anos 2000 a EAD gera, de certa forma, mais flexibilidade em seu acesso e uso com o aperfeiçoamento das tecnologias digitais, muitas delas geradas com o uso da internet. Os processos de interação não existem somente no modo presencial. A partir da rede de computadores - e outros meios, como celulares, tablets, entre outros - a distância tende a ser minimizada e seu aproveitamento, em relação a construção do conhecimento através de trocas entre os indivíduos, torna-se melhor e de maior amplitude. Porém, para cada curso ofertado à distância, há a demanda por espaços onde os conteúdos ofertados e essas relações de interação possam ocorrer de forma satisfatória.

\section{Trajetória histórica da EAD no Brasil}

A EAD surge, de forma oficial, através da LDB (Lei de Diretrizes e Bases), do ano de 1996. Porém, sua definição, na interpretação legal, aparece no Decreto $n^{\circ} 5.622 / 2005$, que é revogado. Em seu lugar, aparece o Decreto n ${ }^{\circ}$ 9.057/2017 onde, em seu Art. $1^{\circ}$ assinala que, 
considera-se educação a distância a modalidade educacional na qual a mediação didático-pedagógica nos processos de ensino e aprendizagem ocorra com a utilização de meios e tecnologias de informação e comunicação, com pessoal qualificado, com políticas de acesso, com acompanhamento e avaliação compatíveis, entre outros, e desenvolva atividades educativas por estudantes e profissionais da educação que estejam em lugares e tempos diversos (Decreto $\mathrm{n}^{\circ}$ 9.057, 2017).

Isso já reflete diferenças em relação ao conceito de EAD já apresentado por autores anteriores aa esse Decreto. Aqui já está sendo abarcado que os cursos devem levar e consideração a variedade de tempo de acesso entre professores e alunos. Além disso, prevê-se a construção de metodologias que auxiliem a mediação nos cursos, tornando-os mais acessíveis. Outro ponto importante deste Decreto é em relação a qualificação dos profissionais dos cursos. Em definições anteriores, não havia menção a este quesito. Ainda não era levado em consideração que as particularidades do ensino a distância demandavam professores familiarizados com esta modalidade. Em relação à questão jurídica, a EAD ganha uma definição, um conceito. O Decreto $n^{\circ}$ 9.057/2017 vai além da oficialidade da EAD como modalidade. Em seu Art. $8^{\circ}$, é estabelecido a abrangência da mesma em vários níveis e modalidades,

\footnotetext{
I - ensino fundamental, nos termos do $\S 4^{\circ}$ do art. 32 da Lei $n^{\circ} 9.394$, de 20 de dezembro de 1996;

II - ensino médio, nos termos do $§ 11$ do art. 36 da Lei no 9.394, de 1996;

III - educação profissional técnica de nível médio;

IV - educação de jovens e adultos; e

V - educação especial. (Decreto $\left.n^{\circ} 9.057,2017\right)$.
}

A partir disso, nota-se o grande alcance desta modalidade. Outro aspecto se refere a adequação de seu alcance as leis de ensino já existentes, tais como a LDB. Em relação a legislação, a EAD encontra-se em conformidade com a mesma. Com relação ao Ensino Superior, as instituições abrangem os cursos de graduação, pós-graduação latu sensu e stricto sensu, tanto para as redes privada e pública.

Acompanhando, de certa forma, o cenário global, o Brasil também possui uma trajetória histórica no âmbito da EAD. Alguns autores, como J. R. M. Alves (1994), Maia e Mattar (2007), B. Carvalho (2014) e Batista e Souza (2015), apontam que a EAD no Brasil tem início no século XX. Por acompanhar o começo e a expansão da EAD no mundo, as cartas foram os primeiros recursos usados nos cursos. Em seguida, com a evolução das tecnologias, os cursos em EAD serviram-se do rádio, televisão, vídeos. Com a difusão da internet, a EAD aumenta seu acesso pelo Brasil. Segundo Maia e Mattar (2007),

Comparando o desenvolvimento da EaD no Brasil com a experiência mundial, algumas diferenças saltam aos olhos. Em um primeiro momento, a EaD brasileira segue o movimento internacional com a oferta de cursos por correspondência. 
Entretanto, mídias como o rádio e a televisão serão exploradas com bastante sucesso em nosso país, por meio de soluções específicas e muitas vezes criativas, antes da introdução da Internet (Maia \& Mattar, 2007, p. 23).

A EAD no Brasil tem sua expansão no mesmo período em que as mídias de comunicação, como rádio e televisão, se expandem no país. O ensino por correspondência acaba por ter um destaque menor.

Em 1923 houve a criação da Rádio Sociedade do Rio de Janeiro, por Henrique Moreze e Roquete-Pinto. Ali eram oferecidos cursos de português, inglês, literatura, telefonia, etc (J. R. M. Alves, 1994; Maia \& Mattar, 2007; B. Carvalho, 2014; Batista \& Souza, 2015).

No ano de 1934, foi criada a Rádio Escola Municipal no Rio. Segundo Maia e Mattar (2007), além do rádio, os "alunos tinham acesso prévio a folhetos e esquemas de aulas, e a Rádio-Escola utilizava também correspondências para contato com os alunos" (Maia \& Mattar, 2007, p. 24). Ainda nos anos 1930, houve a criação do Instituto Monitor, em 1939. Para Batista e Souza (2015), esse projeto "oferecia cursos profissionalizantes à distância com material impresso enviados por correspondência” (Batista \& Souza, 2015, p. 12).

Nos anos 1940, houve a fundação do Instituto Universal Brasileiro, o IUB, em 1941. Segundo Maia e Mattar (2007), os materiais eram apostilas enviadas por correspondência. No ano de 1947, através do grupo SENAC, SESC e emissoras associadas, foi criada a Universidade do Ar. O objetivo desta instituição era oferecer cursos radiofônicos (Maia \& Mattar, 2007; B. Carvalho, 2014). Esses cursos foram ofertados até 1961, quando ocorreu o fim da Universidade do Ar.

O destaque nos anos 1960 vem com a implantação do MEB, Movimento de Educação de Base, que já movimentava ações desde 1959. Juntamente com a CNBB - Conferência Nacional de Bispos do Brasil - e o Governo Federal, segundo Maia e Mattar (2007), iniciou um "sistema radioeducativo para a democratização do acesso à educação, promovendo o letramento de jovens e adultos" (Maia \& Mattar, 2007, p. 26). No final dos anos 1960, fundou-se o Projeto SACI, Satélite Avançado de Comunicação Interdisciplinar, em 1967. Tinha como objetivo instaurar um sistema a nível nacional, de telecomunicações via satélite (Maia \& Mattar, 2007; B. Carvalho, 2014). Segundo Maia e Mattar (2007), a "ideia do projeto Saci era inovadora e pioneira, vislumbrando as possibilidades dos meios de comunicação de massa em favor da prestação de serviços educacionais” (Maia \& Mattar, 2007, p. 26).

Vale ressaltar que, para B. Carvalho (2014), o contexto onde foi implantada a EAD no Brasil, até os anos 1960, objetivou-se uma melhor formação da classe trabalhadora. Segundo a autora "o objetivo era fornecer ao proletariado, via EAD, o que lhe foi negado no ensino 
presencial: o contato e a apropriação de formas mais elevadas e desenvolvidas de cultura e das objetivações do gênero humano" (B. Carvalho, 2014, p. 134).

No ano de 1964 foi instaurado o Governo Militar. Houve várias mudanças em todos os setores da sociedade. A educação foi afetada em suas políticas de implantação. Para B. Carvalho (2014),

No âmbito da produção de conhecimento pela classe hegemônica no poder, a educação escolar foi vista como um instrumento utilizado pelo Regime para assegurar a dominação necessária para o exercício de uma política subordinada e mantenedora do processo de acumulação de capital, tentando, dessa forma, afastar os conflitos e tensões existentes na luta pela hegemonia (B. Carvalho, 2014, p. 136).

O ensino moldou-se, nesse período, de forma mais tecnicista. Assim, objetivava-se o ensino voltado para o mercado de trabalho, não havendo brechas para a reflexão daquilo que se aprendia.

Em 1970 se iniciou o Projeto Minerva, tendo como recursos o rádio e a TV. Segundo B. Carvalho (2014), o objetivo era sanar os problemas que ocorriam com a educação. Assim, este projeto "foi implantado como uma solução em curto prazo para os problemas do desenvolvimento do País, que tinha como cenário um período de crescimento econômico que demandava um rápido preparo de mão-de-obra" (B. Carvalho, 2014, p. 134). Ou seja, o projeto Minerva preparava os alunos para o mercado de trabalho em um tempo menor. Sobre este projeto, Maia e Mattar (2007) apontam que ele visava "a educação e a inclusão social de adultos" (Maia \& Mattar, 2007, p. 27). O projeto teve fim até o início dos anos 1980.

O Telecurso, com início de suas atividades no ano de 1977, é uma parceria entre o Canal Futura, a Fundação Roberto Marinho, a CNI (Confederação Nacional da Indústria) e a FIESP (Federação das Indústrias do Estado de São Paulo). Tem como principal veículo de transmissão a televisão, mas também utilizou materiais impressos. B. Carvalho (2014) aponta que, inicialmente, esse programa "era voltado para pessoas com mais de vinte e um anos que pretendiam fazer os exames supletivos oficiais para obter certificado de conclusão do $2^{\circ}$ grau (atual ensino médio)" (B. Carvalho, 2014, p. 135). Atualmente o programa recebe o nome de Telecurso 2000. Segundo Maia e Mattar (2007) o Telecurso foi um importante marco na EAD no Brasil.

Os anos 1990 são importantes para a expansão da EAD. Em 1995, o programa Salto para o Futuro, antes denominado Jornal da Educação: Edição do Professor, foi vinculado ao canal Tv Escola. Segundo Maia e Mattar (2007), o Salto para o Futuro,

É um programa para formação continuada e aperfeiçoamento de professores (principalmente do ensino fundamental) e alunos dos cursos de magistério. Utiliza 
diversas mídias como material impresso, TV, fax, telefone e Internet, além de encontros presenciais nas telessalas, que contam com a mediação de um orientador de aprendizagem. Os programas são ao vivo e permitem interação dos professores presentes nas telessalas (Maia \& Mattar, 2007, p. 27).

Os anos 1990, através deste programa, foi um importante período para a formação continuada de professores. Não havia menção anterior, por parte dos autores utilizados nesta pesquisa, a cursos voltados para professores. Atualmente há cursos a distância voltados não somente a formação continuada, mas também a formação inicial de professores.

Batista e Souza (2015) afirmam que é a partir da internet que a EAD ganha grandes proporções. Segundo as autoras,

a partir da segunda metade dos nos 1990 a informática ganha maior proporção. Posteriormente, ao computador foi agregada a rede mundial de computadores, capaz de conectar, em tempo real, informações de todo o mundo em apenas um clique. A modalidade de ensino a distância passa, então a se expandir pela internet (Batista \& Souza, 2015, p. 13).

A internet para a ser um importante recurso para os cursos a distância. Isso se deve a sua facilidade em relação ao acesso dentro dos cursos. Além disso, a distância tende a ser atenuada, pois há a possibilidade de professores e alunos estarem conectados, mesmo estando em lugares diferentes.

No ano de 2006 é criado o sistema Universidade Aberta do Brasil (UAB), devido ao Decreto $n^{0} 5.800 / 2006$. Em relação a estrutura dessa instituição, a mesma envolve a parceria entre Governo Federal, as Instituições Públicas de Ensino Superior (IPES), além dos Estados e Municípios. Com relação aos objetivos e abrangência, o Decreto aponta como principais objetivos,

I - oferecer, prioritariamente, cursos de licenciatura e de formação inicial e continuada de professores da educação básica;

II - oferecer cursos superiores para capacitação de dirigentes, gestores e trabalhadores em educação básica dos Estados, do Distrito Federal e dos Municípios;

III - oferecer cursos superiores nas diferentes áreas do conhecimento;

IV - ampliar o acesso à educação superior pública;

$\mathrm{V}$ - reduzir as desigualdades de oferta de ensino superior entre as diferentes regiões do País;

VI - estabelecer amplo sistema nacional de educação superior a distância; e VII fomentar o desenvolvimento institucional para a modalidade de educação a distância, bem como a pesquisa em metodologias inovadoras de ensino superior apoiadas em tecnologias de informação e comunicação (Decreto $n^{\circ}$ 5.800, 2006).

A UAB surge como forma de abranger um maior acesso à universidade pública, através dos cursos ofertados. É uma forma de diminuir as formas desiguais de acesso ao Ensino Superior. 
Para Maia e Mattar (2007), a UAB é considerada um marco da EAD no Brasil, com destaque do mesmo nível de outros países que já haviam passado por essa experiência, como Venezuela, Costa Rica, nos anos 1970. Vale ressaltar que o surgimento da UAB no Brasil ocorreu tardiamente se comparado as outras instituições de outros países, como os já citados.

Como em todos os processos envolvendo o ensino, educação, há contextos que envolvem sua formação, significação e ressignificação e suas funções. Houve várias formas de processos de ensino e educação. Por demandas várias, houve a necessidade de que a educação ocorresse a distância, seja por meio de cartas, rádio, televisão, internet e outros meios digitais. Cada uma das gerações apresentadas se coloca em contextos históricos distintos. Nesse sentido, cada um destes períodos apresenta ferramentas e recursos diferentes, próprios de cada época.

Além disso, cada década - ou período - tem um contexto específico, o que deve ser levado em consideração no momento de estudar os conceitos de EAD. A trajetória histórica desta modalidade deve ser analisada para melhor entender os processos que levam a estruturação na nomenclatura, definição, além dos recursos que se apresentam em cada período que levaram a situação da EAD hoje.

\section{Recursos de interação e formação informais por meio virtual}

A EAD, mesmo se tratando de uma relação de construção de conhecimento através de uma distância física entre as pessoas - ainda que estejam em uma mesma localidade, como uma cidade - possui, em seus objetivos, oportunizar interações que diminuam os possíveis impactos causados pelo distanciamento. Nesse sentido, vários sites que oferecem cursos na modalidade a distância trabalham em recursos que forneçam ambientes de interação e formação por meio virtual.

Silva et al. (2015) destacam a importância das tecnologias de comunicação, onde as mesmas tornam possível uma melhor interação entre as pessoas envolvidas, não importando a distância.

Behar (2009) faz a relação entre as novas urgências dentro do ensino e na educação como um todo. A autora aponta que a atual sociedade centra em um estudo centrado para o mercado de trabalho - onde a tecnologia não é utilizada para a construção do conhecimento e da aprendizagem. As novas mudanças convergem para uma sociedade em que a aprendizagem e, portanto, a construção de conhecimento será feita em redes, ou seja, com a atuação 
importantíssima da tecnologia. Porém, em alguns casos, ainda há o objetivo centrado no trabalho mesmo quando a aprendizagem se dá em rede.

Segundo Behar (2009) uma outra forma de promover uma boa mediação no EAD são os ambientes virtuais de aprendizagem (AVA). Segundo Marcia Waquil e Patrícia Behar (2009) "os recursos tecnológicos de comunicação do AVA são utilizados para as trocas e o enriquecimento mútuo dos sujeitos" (Waquil \& Behar, 2009, p. 151).

Behar (2009) faz uma crítica a algumas formas de promover a EAD. Segundo ela, há uma grande demanda pelo melhoramento tecnológico - ferramenta importante dessa modalidade de ensino. Porém esse melhoramento tecnológico ocorre, em muitos casos, em detrimento a questão pedagógica do ensino.

Atualmente não há como dissociar a EAD da introdução das novas tecnologias. Como já dito anteriormente, o fato de haver tecnologias que permitam outra utilização para cursos e conteúdos de diversos tipos, não há garantias para que haja outras metodologias próprias para isso. Ocorre, em muitos casos, a simples transposição de uma metodologia tradicional para a EAD. Os espaços de trocas de conhecimentos ambientados no meio digital e da web tem sido influenciado pelo modelo próprio do ambiente presencial. Nesse contexto, é necessário que haja um planejamento diferenciado para a EAD. Segundo Amarilla (2011),

não basta codificar um conjunto de saberes em ambientes virtuais para que se estabeleça uma relação pedagógica de ensino, mas que é necessário, também, estabelecer, sistematizar e organizar metodologias e didáticas específicas para a interação dos envolvidos no processo, a saber, professor e aluno (Amarilla, 2011, p. 42).

O ensino a distância, neste sentido, deve levar em consideração alunos e professores e suas relações com o meio digital e a internet. Além disso, deve haver metodologias próprias para esta modalidade.

Para o ensino à distância, o modelo pedagógico deve ser inédito, adaptado às particularidades da EAD. Em relação aos "bastidores do ensino em rede", ou seja, ao planejamento, Waquil e Behar (2009) salientam a criação de uma nova metodologia, própria ao ensino à distância.

A estrutura pedagógica da EAD não é simples apenas pelo fato de se usar a tecnologia de comunicação - como se essa modalidade dependesse somente dela. Como em todo o modelo pedagógico, necessita-se de um extenso planejamento. As autoras destacam que, dentro dos ambientes de aprendizagem, a mesma deve ocorrer em rede. Nisso, 
busca da construção cooperativa do saber e do conhecimento em rede, tornando-se, assim, parceiros no processo de aprendizagem (Waquil \& Behar, 2009, p. 147).

A aprendizagem ocorre através de um sistema de parceria, onde professores e alunos. O planejamento desta modalidade deve ter como objetivo proporcionar que essa rede de parceria se desenvolva da melhor forma possível.

Nesse contexto, Silva et al. (2015) alertam para a importância das instituições que fazem uso da EAD atentarem para o planejamento dessa modalidade. Nesse sentido, Amarilla (2011) aponta que há uma certa dependência entre os meios tecnológicos digitais e os ambientes virtuais, o que serve de alerta para o cuidado ao planejar esses locais e suas respectivas atividades. Assim,

Isso implica um longo processo de preparação, planejamento, realização, pois, de fato, o que se espera é que os conteúdos sejam postos regularmente, assim como que as atividades, as respostas ou as avaliações cheguem a um tempo "curto", pois, este tempo é que influenciará o processo de ensino-aprendizagem (Amarilla, 2011, p. $50)$.

Um curso a distância não pode ser colocado em prática de forma rápida, pois esta é uma das etapas finais. Primeiro deve haver um longo processo, envolvendo a escolha do público alvo, planejamento metodológico, de escolha dos profissionais, de construção da estrutura e dos ambientes virtuais de aprendizagem, entre outros. Por fim, um curso é ofertado. Além disso, há sempre a reflexão sobre os andamentos destes cursos, o que torna necessário sua constante atualização.

O planejamento, quando bem feito, possui mais garantias de que as ações realizadas nos ambientes virtuais obtenham sucesso. Com isso, para Amarilla (2011) "ambientes virtuais em que se pensa realizar um curso, uma aula, são coeficientes necessários para a gestão das condições de acesso e eficiência do processo pedagógico" (Amarilla, 2011, p. 50).

Os ambientes virtuais estão em constante manutenção. Com isso em mente, o pesquisador deve estar ciente dessa característica do objeto de pesquisa na pesquisa.

A partir dessa dinamicidade, entendemos o AVA como um espaço em que há um intenso movimento em que as coisas estão sempre em um processo de vir a ser. A estabilidade, tanto do ambiente como dos usuários, é sempre provisória, pois está sujeita a ações imprevistas e incontroláveis que alimentam a complexidade dialógica do contexto. Considerando essa característica, no momento em que pesquisamos os AVAs não os reduzimos aos indivíduos ou à totalidade que compreende esses ambientes. A dialógica entre o indivíduo e o AVA como um todo deve ser pensado em um mesmo espaço (Waquil \& Behar, 2009, p. 156).

É necessário que estes ambientes passem por um processo de reflexão sobre seu desenvolvimento. Isso gera constantes mudanças e atualizações em sua estrutura. 
A relação entre AVA e usuários é de uma troca interdependente,

Percebemos, assim que nesse ambiente há espaço para que, no lugar de uma posição de manipulação e de controle externo, o sujeito encontre possibilidades de construção/desconstrução/reconstrução/organização de seu conhecimento. Ele depende do ambiente como fonte de informação e de relações que o auxiliam a se auto organizar, mas ele também é fundamental para que o ambiente seja constantemente realimentado de novas ideias, interações, sentimentos produzidos pelo sujeito (Waquil \& Behar, 2009, p. 157).

As constantes modificações dentro da estrutura dos AVA's devem ter como objetivo o auxílio aos alunos dentro de sua aprendizagem. Mesmo que os alunos possuam suas organizações para o estudo, estes espaços devem potencializar essa organização, de forma que eles conheçam outras formas de construir seu conhecimento individual e coletivo.

Nesse sentido, os ambientes virtuais tornaram possível uma maior interação entre os participantes dos cursos. Estes espaços proporcionam um maior resultado em relação ao conhecimento construído pelos alunos, podendo estender-se para além desses ambientes. Segundo Amarilla (2011),

O ânimo que a Educação a Distância recebeu a partir do advento da rede de informação trouxe para essa modalidade de ensino o conceito de "comunidade cooperativa" do conhecimento, em que o conhecimento pode ser construído não apenas pela via do professor-aluno, mas também pela via aluno-aluno e por uma memória coletiva mais acessível (Amarilla, 2011, p. 51).

Essa cooperação entre alunos e professores e entre alunos e alunos geram uma rede de conhecimentos, construídos coletivamente. Assim, a partir dos ambientes virtuais, os conhecimentos passam por um processo de construção que vai além da interação entre aluno e professor. Pela amplitude que esses lugares alcançam, eles acabam por proporcionar as relações entre os participantes dos cursos - alunos. Apesar das atividades contarem com o acréscimo da distância, esses recursos possibilitam um contato que oportuniza a troca de informações, dúvidas e estudos sobre o que está proposto nos cursos.

Atualmente os ambientes virtuais demandam uma preocupação quanto a uma metodologia própria para a sua aplicação, assim como a EAD em geral. Em relação aos ambientes virtuais, Amarilla (2011) aponta que se deve "dosar uma pedagogia que foque a importância da leitura, da pesquisa e da compreensão do conteúdo, ao mesmo tempo que propicie a construção do conhecimento de modo colaborativo e comunitário em ambientes virtuais (Amarilla, 2011, p. 51). Para que haja um ambiente colaborativo, os ambientes devem proporcionar formas em que elas se desenvolvam.

As questões envolvendo a organização pedagógica dos ambientes virtuais ainda é uma temática nova, tanto nas instituições que ofertam cursos a distância, quanto nas pesquisas que 
eles demandam. Ao mesmo tempo, com os avanços tecnológicos, os ambientes virtuais requerem um dinamismo no que se refere à manutenção dos recursos utilizados. Enquanto isso ocorre, cresce o interesse na relação entre tecnologias e processos pedagógicos e em como isso reflete nesses espaços. Segundo Amarilla (2011) é importante observar a evolução das tecnologias aplicadas ao ambiente de ensino e seu reflexo sobre o mesmo. Com isso,

Trata-se de perceber as tecnologias de informação e comunicação como parte de uma revolução científica que repercute como revolução tecnológica que perturba, modifica ou transforma o modo como o homem tem acesso ao conhecimento, à apreensão e representação da sua realidade, às relações sociais e como ele se vê e interage diante dessa mesma realidade (Amarilla, 2011, p. 53).

As tecnologias de informação e comunicação não devem estar dissociadas da relação entre alunos, professores e contextos nãos quais vivem. Estas necessitam auxiliar os participantes dos cursos a refletirem sobre a construção de seu conhecimento e do contexto em que vivem.

Ainda se entende os espaços virtuais como ambientes que, de certa forma, acabam por serem influenciados - quando não reproduzem em sua totalidade - os ambientes de estudos que se estabeleceram nos espaços presenciais de ensino. Amarilla (2011) aponta que, em muitos dos ambientes virtuais, "percebem-se movimentos didáticos expositivos, depositários, em detrimento da interação e da colaboração do aluno à participação na construção do conhecimento" (Amarilla, 2011, p. 52). O autor critica a forma como esses recursos utilizados nos ambientes virtuais são moldados à forma do ensino presencial tradicional. Nesse sentido, o aluno - um dos focos dessa modalidade - pode acabar por prejudicar o seu aprendizado. Assim,

Fala-se muito em ambientes de aprendizagens virtuais, sala virtuais, videoaulas, programas de aprendizagem, entre outros. Todavia, a forma como esses ambientes têm sido operados não dá margem à participação efetiva do sujeito, o aluno, na organização e direção do aprendizado (Amarilla, 2011, p. 52).

Muitos destes ambientes são projetados de forma a não viabilizar a participação dos alunos neles. Nisso, não há como haver uma construção significativa do conhecimento. Além disso, pode ocorrer a desistência dos cursos por parte dos alunos.

O papel do professor tem mudado e sido ressignificado à medida em que as demandas em torno do papel da educação pedem novas reflexões nos novos contextos que se apresentam. Na EAD não é diferente. O professor/tutor tem o papel de acompanhamento, de mediação. Conforme Amarilla (2011), ele é denominado professor-animador. Nisso ele é, 
aquele que se move junto com o aluno ao saber e à análise crítica do próprio saber. É aquele que sabe que é preciso se conhecer como ser humano. É aquele que não faz surgir respostas para os problemas, mas as problemáticas, suas relações, as interdependências, as totalidades. É aquele que se faz autônomo no saber, mas depende da necessidade de saber "junto" com o outro; que faz crescer as incertezas sobre as instituições, os indivíduos e que provoca a si mesmo, interrogando-se sobre outras possibilidades. $\mathrm{O}$ professor animador revela ao aluno não o conhecido, mas aponta para o desconhecido (Amarilla, 2011, p. 54).

O professor torna-se, assim, um importante componente da rede de aprendizagem construída nos ambientes virtuais. Através dele, há a mediação entre a estrutura dos cursos a distância e os alunos, não somente aos conteúdos disponibilizados.

Em relação ao planejamento de um ambiente virtual, Amarilla (2011) aponta metodologias e procedimentos didáticos nesses locais. Para tanto o autor divide esses aspectos em quatro quesitos, sendo eles: cultura técnica, comunicação, metodologia - sendo ela subdividida em autonomia, autodisciplina e autodidatismo e problematização - e, por último, tradução de conteúdo. O primeiro quesito se refere a estrutura dos ambientes virtuais como um todo. Amarilla (2011) destaca que a construção e implementação de um ambiente virtual requer um trabalho interdisciplinar. Nisso, a estrutura necessita equipes vindas da "educação, da comunicação e da ciência da computação que, juntas, devem pensar a gestão das condições de acesso e eficiência do processo pedagógico" (Amarilla, 2011, p. 59). Mas não basta apenas chamar pessoas de várias áreas do conhecimento, elas devem estar em conjunto no objetivo de proporcionar um ambiente virtual que estimule a aprendizagem dos alunos, em sentido individual e coletivo. As falhas, nesse sentido, não podem estar atreladas somente a um dos lados pertencentes aos ambientes. Uma estrutura virtual, tecnológica, não está sozinha. Nisso, “o processo de decisão, portanto, não recai apenas sobre as tecnologias, cabendo somente a elas os sucessos e os fracassos dos métodos adotados, mas recai também sobre a pedagogia, em tirar maior e melhor proveito dessas tecnologias" (Amarilla, 2011, p. 60). A tecnologia não trabalha sozinha. A metodologia utilizada nesses ambientes deve estar aliada as tecnologias escolhidas para os cursos.

Sendo um espaço virtual ou presencial, a comunicação é um elemento importante para os processos de ensino-aprendizagem. Em relação ao ensino presencial, a comunicação é um aspecto importante. Porém, na maioria dos casos, isso se aplica à comunicação verbal, oral. Por se tratar de espaços onde os participantes estão separados - no tempo e no espaço - a comunicação em ambientes virtuais assume outras formas de representação. As ferramentas de comunicação devem ter como objetivo, segundo Amarilla (2011), o acompanhamento do aluno(a) em sua trajetória dentro do curso, desde dúvidas e suas explicações, reflexões, até discussões de temas - propostos ou não. A comunicação deve ser direcionada as 
particularidades da EAD. Nisso, por estar em um amplo espaço como o digital, a comunicação deve abarcar várias formas de fala e seus respectivos armazenamentos, pois ne todos estarão ao mesmo tempo acessando o que foi proposto. Para Amarilla (2011), a “comunicação por ambientes virtuais é a possibilidade, embora haja uma dispersão geográfica, e alunos e professores alimentarem simultaneamente o processo de ensinoaprendizagem por uma memória compartilhada, coletiva e cooperativa" (Amarilla, 2011, p. 61). As várias formas de comunicação devem estar em consonância com o ambiente em que está inserido os conteúdos a serem trabalhados, bem como as várias formas de acesso a elas. Para tanto, como já havia proposto Behar (2009), a organização é de suma importância.

Metodologicamente, a EAD promove recursos que visam a uma aprendizagem de forma distante dos demais componentes de um curso específico, onde o mesmo deve ser estimulado a uma autonomia diferenciada em relação ao ensino presencial. Tanto os espaços presenciais, quanto os virtuais de formação devem estimular a autonomia e autodisciplina. Porém, em muitos casos, o que ocorre são estímulos - muitas vezes mal planejados - que acabam por passar a sensação de individualismo e solidão nos alunos. Porém, as instituições, segundo Amarilla (2011), bem como os próprios alunos e demais componentes participantes dos cursos, estão em uma mesma linha de atuação.

A EAD sugere um dinamismo diferenciado por parte de quem participa. Essa modalidade permite que o aluno(a) flexibilize seus horários e locais de estudo. Essa é, na maioria dos casos, o ponto central das propagandas de uma parcela das instituições que ofertam cursos à distância. Uma preocupação, tanto na modalidade presencial, como na EAD, é estimular a autonomia, disciplina no aluno. Amarilla (2011) aponta que o aluno(a) deve se reconhecer enquanto sujeito participante dentro do processo de construção do conhecimento. Nesse sentido, o autor propõe que os ambientes virtuais estimulem as redes de compartilhamento entre os alunos. Nisso eles devem proporcionar,

uma metodologia que vise a despertar as afetividades positivas do aluno, para que ele vá além do "prato feito" dos materiais pré-produzidos; que incentive, oriente e proponha a auto-organização e que desperte a construção do próprio conhecimento (Amarilla, 2011, p. 63).

Os ambientes virtuais, enquanto recursos dentro da EAD, devem ser planejados visando a construção do conhecimento dentro de um processo contínuo de ensinoaprendizagem. Com isso, segundo Amarilla (2011), ao pensar na autonomia, na disciplina a serem estimuladas no aluno(a), os ambientes virtuais devem ser utilizados para potencializar o desenvolvimento de tais atributos. 
Nesse contexto, a observação do percurso percorrido pelo aluno é de suma importância para que problematize os conteúdos em suas várias possibilidades de apresentação. Assim, o feedback dos alunos possibilita a reflexão quanto aos conteúdos distribuídos nos cursos. Além disso, a estruturação destes dentro dos ambientes virtuais deve levar em consideração o estudo sobre quem está participando destes espaços, visando à apropriação dos conteúdos além dos ambientes.

Após a preparação do ambiente, deve-se atentar para o que estará disponível e como será o acesso aos conteúdos propostos. Estes envolvem um conhecimento acerca do uso de recursos de armazenamento digital. Não basta apenas depositar os conteúdos para o acesso feito pelo aluno. Assim, entende-se que o aluno seja um sujeito vazio de conhecimentos. Essa tradução dos conteúdos, para Amarilla (2011) implica em considerar os conhecimentos prévios dos alunos. Além disso, a forma em que ocorre essa tradução de conteúdos deve estimular a procura, por parte do aluno, de novas informações. Nisso,

o plano de tradução é indissociável do plano didático e, por isso, o primeiro deve ser compreendido e elaborado não pela linearidade dos modelos comunicativos, mas, ao contrário, pelas derivações que o processo de ensino-aprendizagem apresentam (Amarilla, 2011, p. 67).

Há uma complexidade no planejamento dentro dos ambientes virtuais. Por estar em um ambiente digital, ainda em processo de entendimento e uso, isso leva a uma contínua reflexão acerca de suas potencialidades. Isso ocorre tanto em relação aos alunos como aos professores e demais atores do processo de ensino-aprendizagem em ambientes virtuais.

\section{Considerações finais}

A partir da presente pesquisa, foi possível perceber como a EAD se desenvolveu, tanto em contexto mundial, como dentro do Brasil. Isso ressalta a importância de se compreender como o seu conceito se construiu. Assim, o planejamento de cursos a distância poderá ser melhor compreendido, bem como contribuir para as reflexões dos cursos já em andamento. Tanto professores quanto alunos necessitam interpretar estas diferentes concepções, visando uma interação nesta modalidade.

Como em todos os processos envolvendo o ensino, educação, há contextos que envolvem sua formação, significação e ressignicação em suas funções. Houve várias formas de processos de ensino e educação. Por demandas várias, houve a necessidade de que a educação ocorresse a distância, seja por meio de cartas, rádio, televisão, internet e outros 
Research, Society and Development, v. 9, n.1, e21911551, 2020

(CC BY 4.0) | ISSN 2525-3409 | DOI: http://dx.doi.org/10.33448/rsd-v9i1.1551

meios digitais. Nesse sentido, cada um dos períodos históricos apresenta ferramentas e recursos diferentes, próprios de cada época. Além disso, cada década - ou período - tem um contexto específico, o que deve ser levado em consideração no momento de estudar os conceitos de EAD. A trajetória histórica desta modalidade deve ser analisada para melhor entender os processos que levam a estruturação na nomenclatura, definição, além dos recursos que se apresentam em cada período que levaram a situação da EAD hoje.

Em meio a isso uma das características que permeiam esses períodos é a comunicação. Nos dias atuais uma das ferramentas usadas nesses cursos a distância são os ambientes virtuais de aprendizagem, bem como de formação. Estes acompanham a própria evolução dos ambientes digitais, além de seus recursos utilizados. Portanto, os potenciais destes ambientes ainda estão em processo de construção e reflexão, tanto em relação as suas atuações dentro dos cursos a distância, quanto nas pesquisas acadêmicas que envolvem essa temática.

Como sugestão para trabalhos futuros, faz-se necessário estudos sobre como alunos e professores compreendem os processos envolvendo o ensino a distância. Além disso, para o enriquecimento das pesquisas sobre esta temática, é indispensável pesquisas que aprofundem a discussão sobre as redes de aprendizagem colaborativas dentro dos ambientes virtuais. Assim, as reflexões sobre estes ambientes influenciam em um desenvolvimento favorável para alunos e professores.

\section{Referências}

Amarilla, P., Fo. (2011). Educação a distância: uma abordagem metodológica e didática a partir dos ambientes virtuais. Educação em Revista, 27(2), 41-72.

Alves, J. R. M. (1994). A educação a distância no Brasil: síntese histórica e perspectivas. Rio de Janeiro: Instituto de Pesquisas Avançadas em Educação.

Alves, L. (2011). Educação a distância: conceitos e história no Brasil e no mundo. Revista Brasileira de Aprendizagem Aberta e a Distância, 10(1), 83-92.

Batista, C. J. F., \& Souza, M. M. (2015). A Educação à distância no Brasil: regulamentação, cenários e perspectivas. Revista Multitexto, 3(02), 11-15. 
Behar, P. A. (Org.) (2009). Modelos pedagógicos em educação a distância. Porto Alegre: Artmed Editora.

Carvalho, B. (2014). Ensino a distância: limites e possibilidades na formação de professores (Dissertação de Mestrado). Universidade Estadual Paulista, Araraquara, SP, Brasil.

Decreto $\mathrm{n}^{\circ} 5.622$, de 19 de julho de 2005. Regulamenta o art. 80 da Lei $\mathrm{n}^{\circ}$ 9.394, de 20 de dezembro de 1996, que estabelece as diretrizes e bases da educação nacional. Recuperado em 27 agosto, 2018, de http://portal.mec.gov.br/sesu/arquivos/pdf/portarias/dec5.622.pdf.

Decreto $\mathrm{n}^{\circ}$ 5.800, de 8 de junho de 2006. Dispõe sobre o Sistema Universidade Aberta do Brasil. Recuperado em 27 agosto, 2018, de http://www.planalto.gov.br/ccivil_03/_ato20042006/2006/decreto/d5800.htm.

Decreto n 9.057, de 25 de maio de 2017. Estabelece a regulamentação da Educação a Distância. $\begin{array}{lllll}\text { Recuperado } & \text { em } & 27 & \text { agosto, } & \text { de }\end{array}$ http://www.planalto.gov.br/ccivil_03/_Ato20152018/2017/Decreto/D9057.htm\#art24.

Garcia, V. L., \& Carvalho, P. M., Jr. (2015). Educação à distância (EAD), conceitos e reflexões. Medicina (Ribeirão Preto. Online), 48(3), 209-213.

Lei n 9.394, de 20 de dezembro de 1996. Estabelece as diretrizes e bases da educação nacional. Recuperado em 27 agosto, 2018, de http://www.planalto.gov.br/ccivil_03/_ato20042006/2006/decreto/d5800.htm.

Luzzi, D. A. (2007). O papel da educação a distância na mudança de paradigma educativo: da visão dicotômica ao continuum educativo (Doctoral dissertation). Universidade de São Paulo, São Paulo, SP, Brasil.

Maia, C., \& Mattar, J. (2007). ABC da EaD: a educação a distância hoje. Pearson Prentice Hall.

Mill, D., \& Oliveira, R. G. (2014). A Educação a Distância em pesquisas acadêmicas: uma análise bibliométrica em teses do campo educacional. Educar em Revista, (4), 15-36. 
Pereira, A. S., Shitsuka, D. M., Parreira, F. J., \& Shitsuka, R. (2018). Metodologia da pesquisa científica. Santa Maria: UAB/NTE/UFSM. Recuperado de https://repositorio.ufsm.br/bitstream/handle/1/15824/Lic_Computacao_Metodologia-PesquisaCientifica.pdf? sequence $=1$.

Santos, N. (1999). Estado da arte em espaços virtuais de ensino e aprendizagem. Revista brasileira de informática na educação, 4(1), 75-94.

Silva, M. P. D., Melo, M. C. D. O. L., \& Muylder, C. F. D. (2015). Educação a Distância em foco: um estudo sobre a produção científica brasileira. RAM. Revista de Administração Mackenzie, 16(4), 202-230.

Vilaça, M. L. C. (2010). Educação a Distância e Tecnologias: conceitos, termos e um pouco de história. Revista Magistro, 2(2), 89-101.

Waquil, M. P., \& Behar, P. A. (2009). Princípios da pesquisa científica para investigar ambientes virtuais de aprendizagem sob o ponto de vista do pensamento complexo. In Behar, P. A. (Org.), Modelos pedagógicos em educação a distância. Porto Alegre: Artmed Editora.

\section{Porcentagem de contribuição de cada autor no manuscrito}

Stéfani Martins Fernandes - 30\%

Leonardo Guedes Henn - 35\%

Liane Batistela Kist $-35 \%$ 